\title{
JEJAK BUDAYA PENUTUR AUSTRONESIA PADA SITUS KAMPUNG FORIR, FAKFAK \\ (The Last Vestiges of The Austronesian Culture in Kampung Forir Site, Fakfak)
}

\author{
Sri Chiirullia Sukandar \\ Balai Arkeologi Jayapura, Jalan Isele, Kampung Waena, Jayapura 99358 \\ Telepon (0967) 572467, Faksimile (0967) 572467, e-mail: schiirullia@yahoo.com
}

\section{INFO ARTIKEL}

Histori artikel:

Diterima 4 Februari 2015

Direvisi 20 April 2015

Disetujui 4 Mei 2015

\section{Keywords:}

Austronesian,

Sosoraweru Cave,

Forir

Kata kunci:

Austronesia,

Gua Sosoraweru,

Forir

\begin{abstract}
Research on Sosoraweru cave site and Kampung Forir site, shows a number of issues Austronesian context. There are two issue to be discussed in this article, namely: (1) Traces of Austronesian speakers in Kampung Furir; (2) Function Sosoraweru cave site in the past. To explore both of these issues used the method of observation, excavation, and literature and analyzed based on contextual analysis. The baseline data obtained and analyzed in the form of artifacts and ekofak the influence of Austronesian culture in the southwestern coast of Papua. Based on the data and the context concluded that traces the influence of Austronesian in Sosoraweru cave include: red slip pottery fragments, the system of burial niches and frescoes which show the influence of Austronesian cultures. In addition, based on the context of the locus is known that the Sosoraweru cave site and Kampung Forir site serve as a residential in the past.
\end{abstract}

\begin{abstract}
Abstrak
Penelitian di Situs Kampung Forir dan Gua Sosoraweru memperlihatkan sejumlah konteks isu Austronesia. Ada dua masalah yang akan dibahas dalam artikel ini, yaitu: (1) Jejak penutur Austronesia di Kampung Furir; (2) Fungsi situs Gua Sosoraweru di masa lalu. Untuk mendalami kedua masalah tersebut, digunakan metode observasi, ekskavasi, dan studi pustaka. Data-data pokok yang diperoleh dianalisis berdasarkan analisis kontekstual, berupa artefak dan ekofak untuk melihat adanya pengaruh budaya Austronesia di kawasan pesisir baratdaya Papua. Berdasarkan data dan konteksnya disimpulkan bahwa jejak pengaruh Austronesia di Gua Sosoraweru meliputi: fragmen gerabah berslip merah, sistem penguburan ceruk dan lukisan dinding yang menunjukkan adanya pengaruh budaya Austronesia. Selain itu, berdasarkan konteks lokus temuan diketahui bahwa Gua Sosoraweru dan kawasan Kampung Forir berfungsi sebagai hunian di masa lalu
\end{abstract}

\section{PENDAHULUAN}

Dalam sejarah sebaran manusia, persebaran Austronesia yang berlangsung dalam kurun waktu 50001000 tahun yang lalu pada kawasan yang sangat luas, merupakan sebuah pencapaian yang besar. Penguasaan teknologi pelayaran dalam hal membuat perahu, pengetahuan astronomi dan arah angin, serta kemampuan mengorganisasikan pelayaran jauh, memungkinkan mereka untuk menyebar dalam kawasan yang sangat luas itu. Dengan membatasi pada wilayah pantai sebagai tempat persinggahan tanpa memasuki pedalaman, mereka dapat bergerak lebih cepat hingga jauh ke wilayah Pasifik (Simanjuntak, 2011: 2-3).

Imigran Austronesia yang datang ke Pasifik bermukim di sepanjang tepi pantai. Penghunian wilayah pesisir yang dapat dilakukan dengan mudah dan cepat rupanya lebih diminati, daripada wilayah pedalaman yang lebih membutuhkan tenaga. Di sisi lain, pada beberapa tempat sudah dihuni oleh penduduk yang mungkin tidak bisa menerima para imigran Austronesia tersebut (Suroto, $2010: 35)$. 
Para penutur Austronesia yang bermigrasi ke Melanesia lebih memilih untuk tetap bermigrasi pada jalur laut, serta beradaptasi pada lingkungan kepulauan dan pesisir yang halangannya rendah. Hal ini lebih menguntungkan karena mereka tidak akan menghadapi halangan pengetahuan, sebab mereka telah terbiasa dan amat memahami lingkungan kepulauan dan pesisir. Mereka akan dapat bergerak lebih cepat karena tidak perlu mengubah budaya baharinya (Tanudirdjo, 2011: 37).

Papua telah menjadi jalur perlintasan kelompok penutur bahasa Austronesia kurang lebih sejak 3500 tahun yang lalu. Dengan posisi geografisnya, Papua selain menyerap budaya Melanesia dari Pasifik, juga mendapat pengaruh dari Austronesia. Sisa-sisa interaksi yang menandai kehadiran budaya Austronesia dan Melanesia di Papua serta tradisi prasejarah berlanjut masih dapat ditemukan bukti-buktinya sampai sekarang (Mahmud, 2011: 44).

Menurut Spriggs (dalam Tanudirjo, 2011: 25), terdapat beberapa jenis artefak yang dianggap dapat menunjukkan interaksi budaya penutur Austronesia dan masyarakat Melanesia sekitar 3500 tahun yang lalu. Jenis-jenis artefak tersebut antara lain gerabah, beliung persegi, pahat batu poles, batu penumbuk biji, artefak kerang conus, kail kerang, rumah berdenah persegi, dan perkampungan terbuka. Selain itu, unsur budaya lain yang diduga diperkenalkan para penutur Austronesia ke masyarakat Melanesia di antaranya adalah memelihara ternak babi, ayam dan anjing serta tradisi kunyah pinang. Seni cadas (rock art) juga menunjukkan bahwa di Melanesia hasil budaya ini lebih banyak merupakan pengaruh dari budaya Austronesia. Sebaran dua jenis seni ini yaitu, seni gores dan seni lukis ternyata menunjukkan pola-pola yang mirip dengan sebaran bahasa di Melanesia dan Indonesia Timur (Tanudirdjo, 2011: 25).

Tinggalan arkeologi di Kabupaten Fakfak menunjukkan adanya jejak dari budaya Austronesia, antara lain seni cadas (rock art)pada dinding-dinding tebing maupun di dinding gua (Tim Peneliti, 2009). Selain itu, temuan-temuan fragmen gerabah di situs Gua Sabiberau Kampung Andamata, Gua Sosoraweru di Kampung Forir, Gua Ondarewa dan Gua Tig-Tig di Kampung Goras (Awe, 1996). Diperkirakan gerabah mulai dikenal di Papua setelah adanya kontak dengan penutur Austronesia (Suroto, 2010 : 42).

Wilayah Kabupaten Fakfak memiliki luas $14.320 \mathrm{~km}^{2}$. Fakfak merupakan salah satu Kabupaten di Propinsi Papua Barat, beribukota di Kota Fakfak. Secara geografis terletak di $131^{\circ} \mathrm{o} 30^{\prime}-138^{\circ}, 40^{\prime}$ BT dan antara $2^{\circ} 25^{\prime}-4^{\circ} 00^{\prime}$ LS. Daerah ini berbatasan langsung dengan Teluk Bintuni di sebelah utara, Laut Arafura dan Kabupaten Kaimana di sebelah selatan, Laut Seram dan Teluk Berau di sebelah barat, serta Kabupaten Kaimana di sebelah timur. Kabupaten Fakfak terdiri dari sembilan distrik, yaitu: Distrik Teluk Patipi, Fakfak Barat, Fakfak Kota, Kokas, Kramongmongga, Fakfak Tengah, Bomberai, Fakfak Timur, dan Karas. 


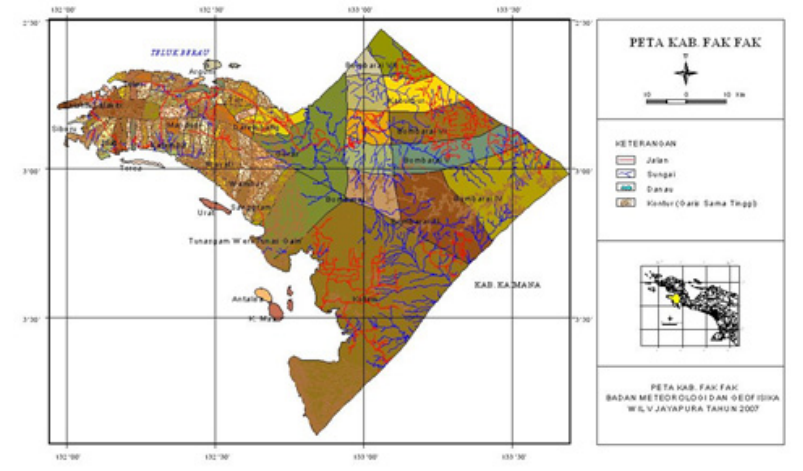

Gambar 1. Peta Kabupaten Fakfak Sumber: Badan Meteorologi dan Geofisika

Distrik Kokas secara fisiografis terletak pada wilayah perbukitan Fakfak di Teluk Berau. Wilayah distrik ini, di samping berada pada daratan besar Papua juga mencakup pulau-pulau di sekitarnya, seperti Pulau Arguni, Pulau Ugar dan beberapa pulau kecil lainnya. Pantai dan pulau-pulau pada daerah ini pada umumnya merupakan pantai dan pulau-pulau karang, sehingga keadaan vegetasi di daerah ini umumnya berupa vegetasi pantai pasir dan karang.

Sejauh ini, penelitian yang pernah dilakukan di Kampung Forir masih bersifat survei permukaan, belum dilakukan ekskavasi. Oleh karena itu, penelitian dengan ekskavasi di wilayah Forir (Fakfak) penting untuk dilakukan, berdasarkan informasi dan data awal survei sebelumnya. Dengan ekskavasi diharapkan dapat memperoleh data arkeologi yang beragam, terutama secara vertikal.

Dalam tulisan ini akan mendiskusikan dua maslah pokok. Pertama, apa jejak budaya penutur Austronesia di Kampung Forir. Kedua, bagaimana fungsi kawasan
Kampung Forir dan Gua Sosoraweru di masa lalu. Kedua masalah tersebut diungkapkan dengan tujuan untuk mengetahui jejak migrasi penutur Austronesia yang melewati wilayah Kepala Burung Papua. Selain itu, tulisan ini juga akan bertujuan mengungkap pemanfaatan Gua Sosoraweru pada masa lalu melalui ekskavasi. Situs Gua Sosoraweru, pernah dilakukan survei oleh Rokus Due Awe pada tahun 1996 dan oleh Tim Peneliti Balai Arkeologi Jayapura pada tahun 2009 yang menemukan cangkang moluska dan fragmen gerabah.

\section{METODE PENELITIAN}

Penelitian Arkeologi di Kampung Forir, Distrik Kokas, Kabupaten Fakfak, Papua Barat ini untuk memperoleh data utama dilakukan dengan cara observasi. Observasi dilakukan guna memperoleh data permukaan di Situs Gua Sosoraweru dan Kampung Forir, serta melakukan pengamatan vegetasi dan lingkungan. Penggambaran dan pengukuran situs juga dilakukan saat observasi ini.

Selain melakukan observasi, guna memperoleh data yang berkaitan dengan jejak penutur Austronesia, juga dilakukan ekskavasi. Ekskavasi dilakukan untuk mengumpulkan data arkeologi yang ada di bawah permukaan tanah. Dalam penelitian ini, sistem yang digunakan adalah sistem kotak (box), dengan ukuran $1 \times 1$ meter digali penuh tanpa menyisakan dinding. Teknik ekskavasinya menggunakan teknik spit yang dilakukan dengan interval kedalamam tiap spit $10 \mathrm{~cm}$. 
Studi Pustaka, dilakukan untuk memperoleh data pendukung berupa gambaran mengenai situs yang akan diteliti, melalui sumber-sumber tertulis berupa buku, laporan-laporan penelitian dan tulisan-tulisan yang berkaitan dengan situs Kampung Forir dan Gua Sosoraweru. Pengolahan data dilakukan dengan cara mendeskripsikan data yang telah ditemukan, untuk kemudian dianalisis serta ditarik kesimpulan.

\section{HASIL DAN PEMBAHASAN}

Data arkeologi merupakan bahan dasar setiap kajian arkeologis, antara lain berupa benda-benda bentukan manusia (artefak), pertanda kegiatan manusia yang tidak terpindahkan (feature) dan benda bukan bentukan manusia di dalam situs arkeologi (ekofak). Data arkeologi sebagai bagian dari budaya masa lampau yang terawetkan diyakini dapat digunakan untuk merekonstruksi berbagai aspek budaya masa lampau (Tanudirdjo, 1995: 14).

Kampung Forir secara administratif terletak di Distrik Kokas, Kabupaten Fakfak, Provinsi Papua Barat. Kampung ini berbatasan dengan Kampung Darembang di sebelah selatan, Kampung Fior di sebelah barat dan utara serta Teluk Berau di sebelah timur. Survei dilakukan di Situs Kampung Lama Forir dan situs lukisan dinding tebing di sekitar Kampung Forir, sedangkan survei dan ekskavasi dilakukan di Situs Gua Sosoraweru.

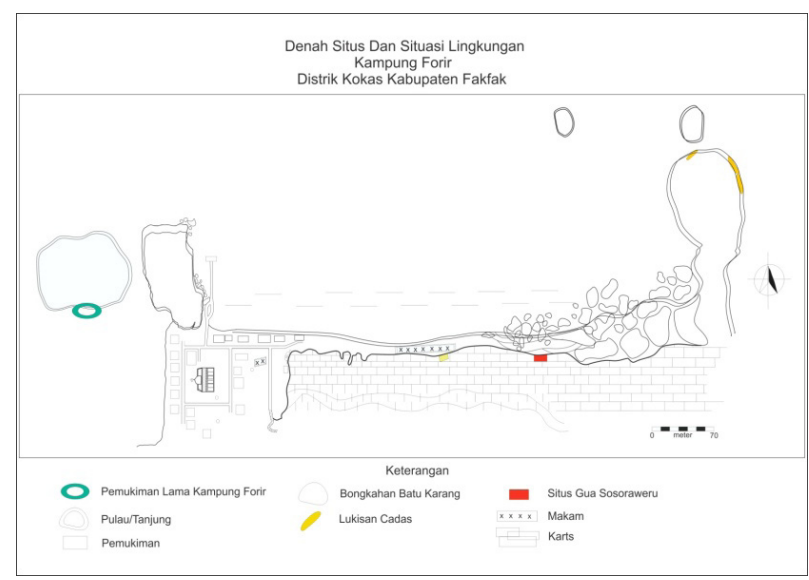

Gambar 2. Denah Situs Kampung Forir (sumber: Balai Arkeologi Jayapura)

\section{Situs Kampung Lama Forir}

Secara astronomis Situs Kampung Lama Forir terletak pada $132^{\circ} 37^{\prime} 452^{\prime \prime}$ Bujur Timur dan 02 43' 058" Lintang Selatan. Bekas Kampung Lama ini terletak di pulau tersendiri berjarak kurang lebih 300 meter arah barat dari Kampung Forir yang ada sekarang ini.

Berdasarkan hasil survei di Situs Kampung Lama Forir, ditemukan tinggalan arkeologi berupa, enam fragmen gerabah berhias. Fragmen gerabah hias tersebut terdiri dari empat fragmen tepian gerabah, satu fragmen badan gerabah dan satu fragmen dasar gerabah. Selain fragmen gerabah berhias, ditemukan pula fragmen gerabah polos sebanyak 23 buah. Gerabah polos terdiri dari 6 fragmen tepian, 14 fragmen badan, 2 fragmen dasar dan 1 fragmen pegangan tutup periuk. Temuan gerabah berwarna hitam dan merah. 


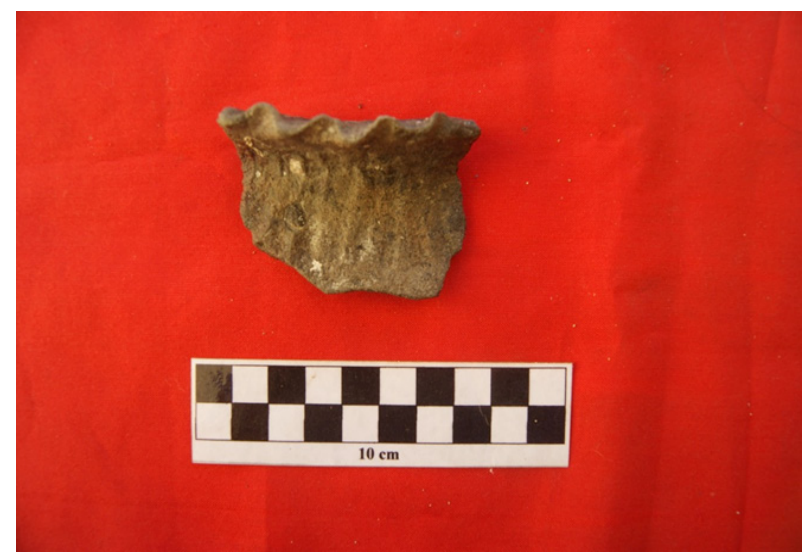

Gambar 3. Fragmen Tepian Gerabah Berhias (dokumentasi Balai Arkeologi Jayapura)

Fragmen keramik juga ditemukan sebanyak 11 buah. Temuan fragmen keramik terdiri dari 4 mangkuk bagian dasar, 1 keramik tepian Eropa, 1 Ming, 2 badan piring Eropa bagian serta 3 bagian dasar piring Ching. Semua temuan tersebut diperoleh dari pinggir pantai di dalam air laut (Sukandar, 2012: 13-14).

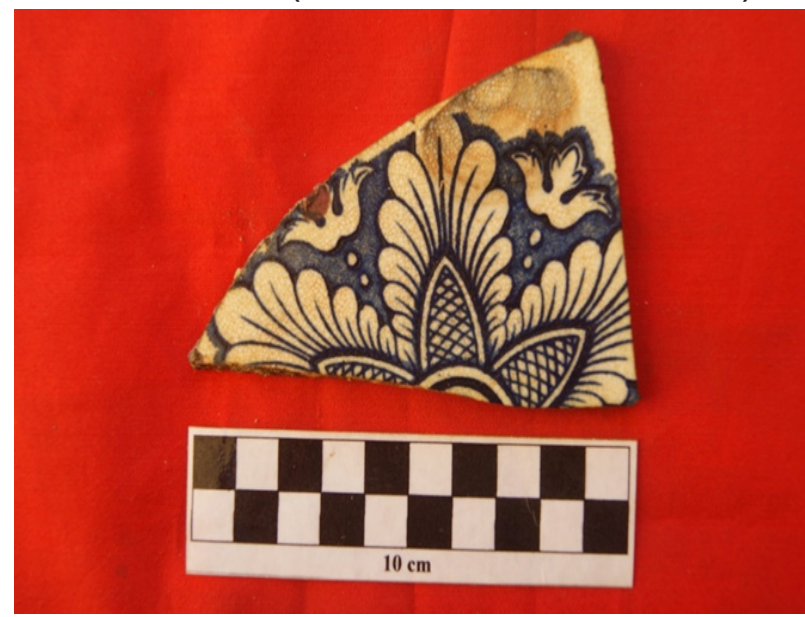

Gambar 4. Fragmen keramik (dokumentasi Balai Arkeologi Jayapura)

\section{Situs Lukisan Dinding Tebing}

Tebing-tebing ini merupakan pulaupulau karang. Dinding-dinding tebing menjulang tegak lurus dari air laut, sedangkan bagian bawahnya telah terkikis oleh air laut. Pada dinding tebing inilah terdapat tinggalan arkeologi berupa lukisan dinding. Tebing-tebing tersebut antara lain:

\section{Tebing Ndamirweru}

Berada pada koordinat $132^{\circ} 37.169^{\prime}$ Bujur Timur dan $02^{\circ}$ 42.895' Lintang Selatan dengan arah hadap timur laut. Lukisan dindingnya terletak pada cerukceruk tebing dengan motif berupa cap tangan (tujuh buah di sisi utara dan tiga di sisi timur), titik dan kura-kura. Lukisan dinding ini berwarna merah.

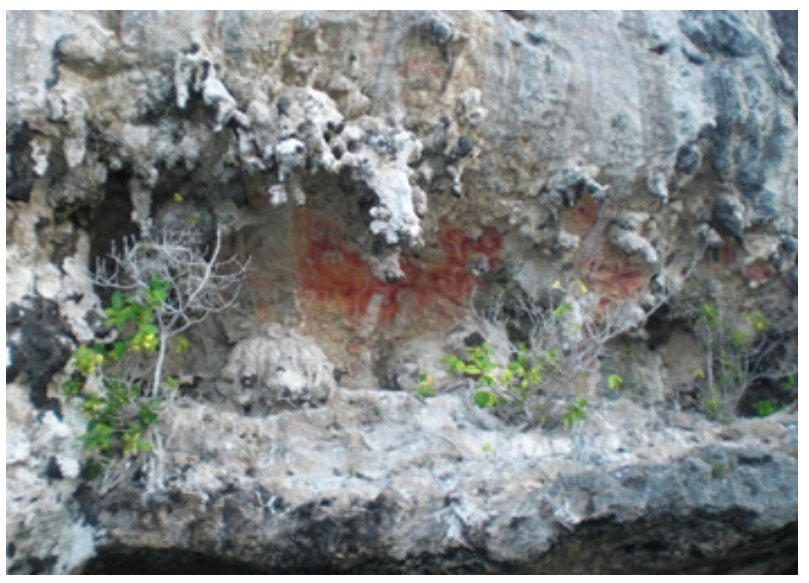

Gambar 5. Tebing Ndamirweru (dokumentasi Balai Arkeologi Jayapura)

\section{Tebing Aintura}

Berada pada koordinat $132^{\circ} 37.255^{\prime}$ Bujur Timur dan 02 ${ }^{\circ}$ 43.048' Lintang Selatan dengan arah hadap timur. Motif lukisannya berupa cap tangan, lingkaran, tanda silang dan titik-titik yang memanjang sampai kurang lebih 30 meter. Lukisan berwarna merah. 


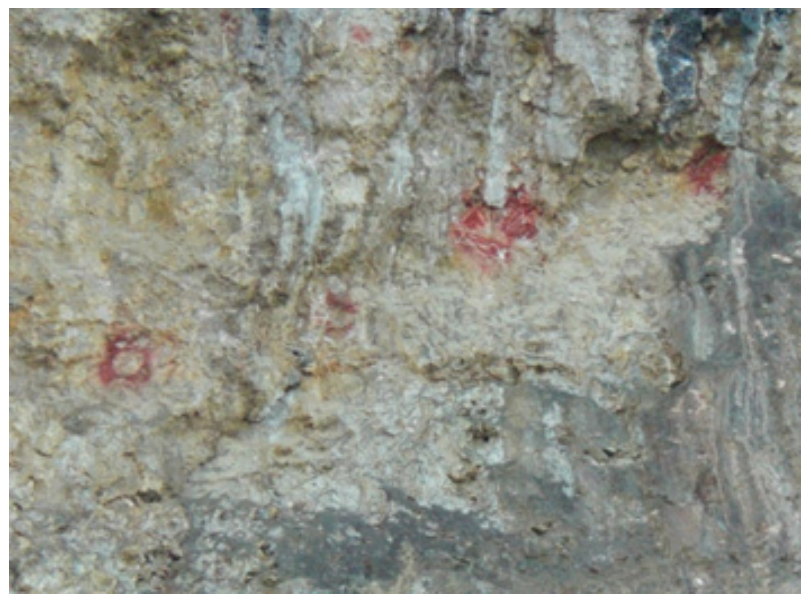

Gambar 6. Tebing Aintura

(dokumentasi Balai Arkeologi Jayapura)

\section{Tebing Fotamramo}

Berada pada koordinat $132^{\circ} 37.219^{\prime}$ Bujur Timur dan $02^{\circ}$ 43.201' Lintang Selatan dengan arah hadap timur. Motif yang ada berupa cap tangan, bintang laut, manusia, bentuk geometris, topeng dan ikan. Lukisan berwarna merah dan kuning (Sukandar, 2012 : 15-16).

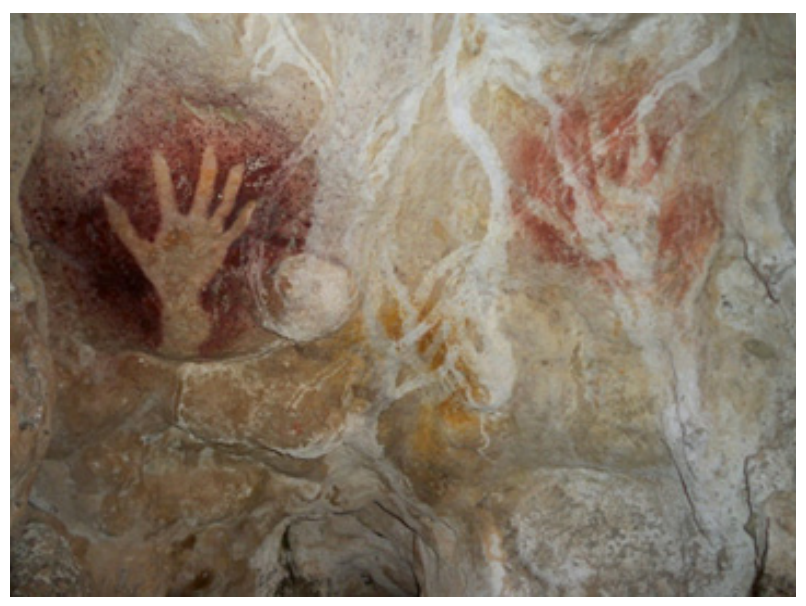

Gambar 7. Tebing Fotamramo (dokumentasi Balai Arkeologi Jayapura)

\section{Situs Gua Sosoraweru}

Gua Sosoraweru secara administratif terletak di Kampung Forir, Distrik Kokas, Kabupaten Fakfak. Letak gua berada di bagian timur Kampung Forir dengan koordinat $132^{\circ} 37.796^{\prime}$ Bujur Timur dan 0243.448' Lintang Selatan. Untuk mencapai gua dapat menggunakan speed atau longboat dari Kokas ke Kampung Forir sekitar satu jam, kemudian ditempuh dengan berjalan kaki menyusuri pantai sejauh kurang lebih 200 meter. Gua ini menghadap ke arah utara dan berada pada sisi lereng tebing, empat meter di depan mulut gua terdapat air laut.

Gua Sosoraweru merupakan gua yang cukup besar. Mulut gua berada pada ketinggian kurang lebih tujuh meter di atas permukaan laut dengan lebar mulut gua lima meter dan tinggi mulut gua tiga meter. Kedalaman atau panjang gua 22 meter dan lebar ruang gua 17 meter. Lantai gua berupa tanah berwarna hitam kecoklatan yang rata di bagian muka dan miring ke bawah di bagian belakang, sehingga permukaan lantai gua di bagian muka lebih tinggi dari pada di bagian belakang. Lantai gua kering di bagian depan dan lembab pada bagian belakang. Dinding gua berupa batu karang, pada langit-langit gua terdapat beberapa stalaktit serta lukisan dinding berwarna hitam dan sudah pudar.

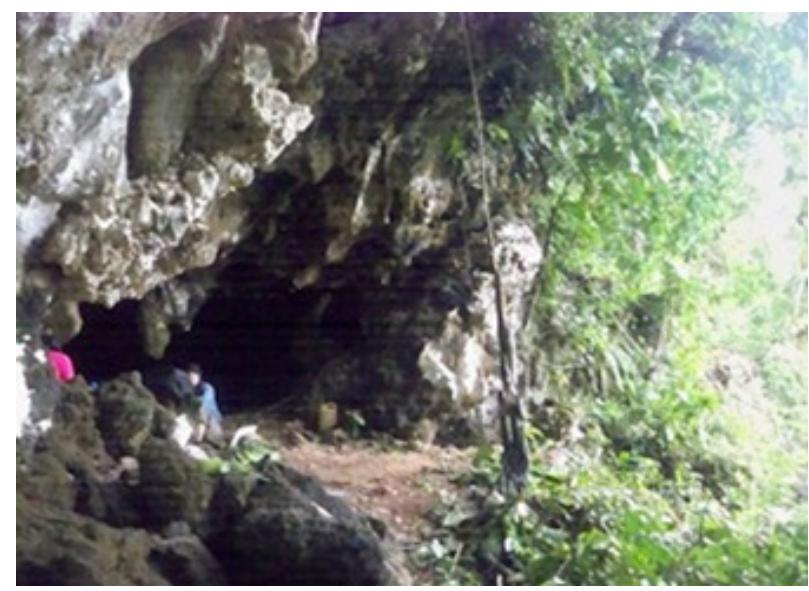

Gambar 8. Gua Sosoraweru (dokumentasi Balai Arkeologi Jayapura)

Kondisi Gua Sosoraweru cukup terang, namun penetrasi sinar matahari tidak dapat menjangkau seluruh ruangan gua. Kurang lebih 300 meter ke arah barat terdapat sumber air tawar berupa sebuah 
mata air. Di depan mulut gua terdapat pohon beringin dan merbau.

Vegetasi sekitar Situs Gua Sosoraweru antara lain pohon meranti, beringin [Sumawinda (nama lokal)], pandan, kelapa dan merbau. Jenis fauna sekitar situs antara lain burung gagak, cenderawasih, taon-taon, mambruk, merpati [Kumkum (nama lokal)], nuri, kakatua, babi hutan, kasuari, kangguru pohon, kuskus, kadal [Soa-soa (nama lokal)], ular, lipan, tikus tanah, laba-laba, kelelawar [paniki (nama lokal)], walet dan rusa.

Hasil survei pada permukaan gua ditemukan beberapa tinggalan arkeologi berupa 22 fragmen gerabah, baik polos maupun berhias yang terdiri dari 2 fragmen gerabah polos bagian tepian, 17 fragmen badan dan 3 fragmen berhias bagian tepian (Sukandar, 2012: 10).
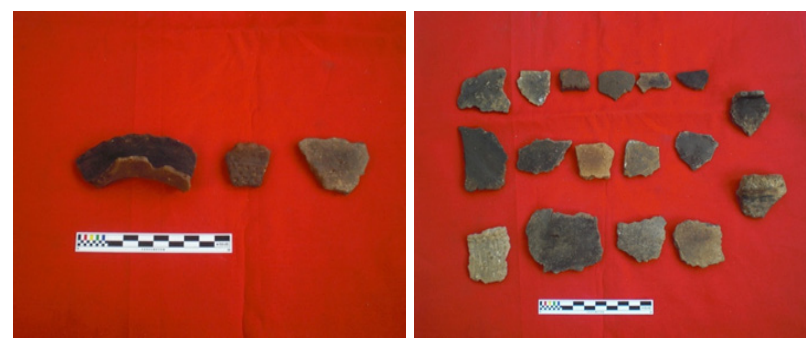

Gambar 9. Fragmen gerabah (dokumentasi Balai Arkeologi Jayapura)

Temuan lain berupa lukisan dinding gua berwarna hitam pada langit-langit gua. Keadaan lukisan dinding ini sudah mulai pudar serta terdapat bekas-bekas penggosokan karena proses pembersihan dari lumut kerak yang menutupi hampir seluruh langit-langit gua. Panel lukisan terletak pada langit-langit gua sisi timur tidak jauh dari mulut gua. Tinggi lukisan dari lantai gua antara 1-2 meter. Lukisan yang ada berupa bentuk geometris seperti garis-garis yang membentuk segi empat dan segi tiga serta lukisan yang belum teridentifikasi karena sudah pudar. Panel lainnya berada di langit-langit bagian tengah gua dengan lukisan abstrak berwarna hitam (Sukandar, 2012:11).

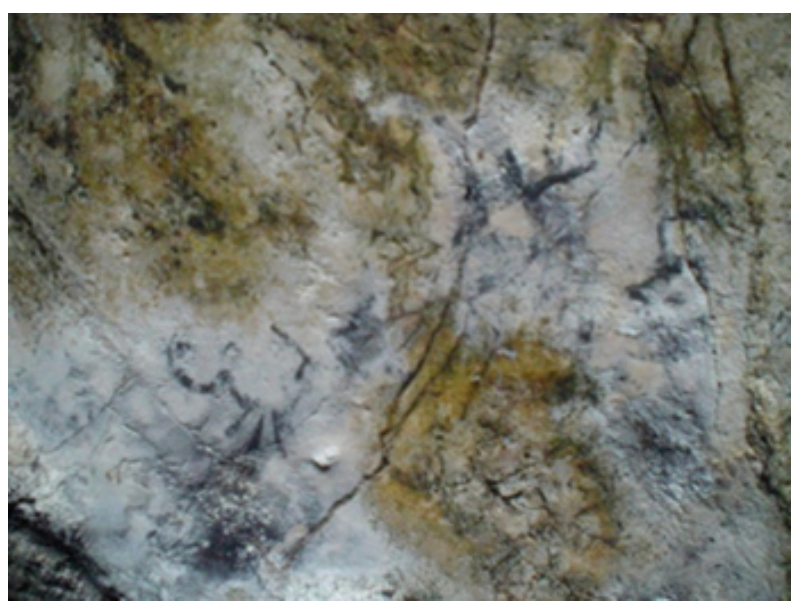

Gambar 10. Lukisan dinding geometris

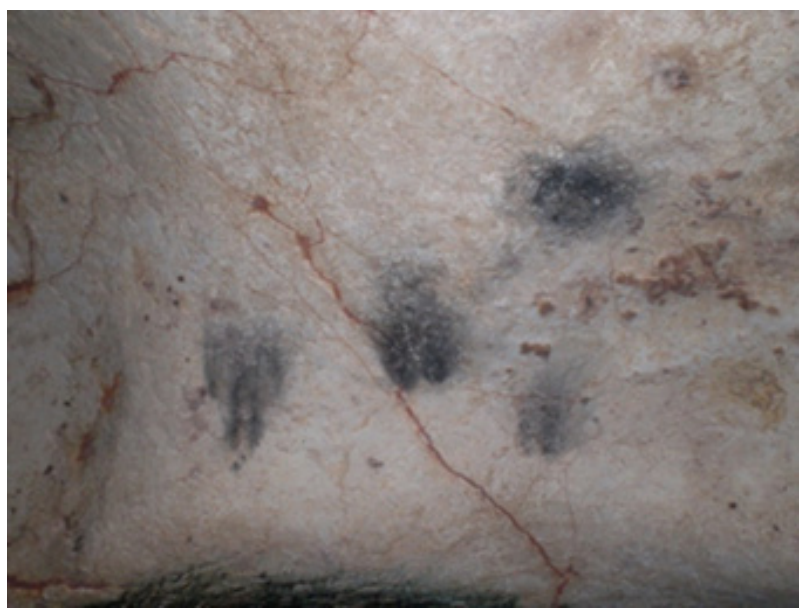

Gambar 11. Lukisan dinding abstrak (dokumentasi Balai Arkeologi Jayapura)

Ekskavasi di Situs Gua Sosoraweru ini dibuka 3 kotak dengan temuan berupa fragmen gerabah, cangkang moluska, fragmen kepiting, fragmen tulang ikan, fragmen tulang binatang, fragmen cangkang kerang yang dibakar, butiran kapur, fragmen kulit / lapisan batu bekas tungku pembakaran, burn clay, alat tusuk, arang, alat tulang, bahan alat batu dan bulu burung.

Pada kotak U4T4 terdapat bekas pembakaran kerang dalam jumlah yang banyak. Selain itu, pada spit 11 terdapat 
bongkahan batu-batu seukuran kepalan tangan orang dewasa sebanyak 6 buah, kemungkinan merupakan dasar atau penopang batu di atasnya. Pada spit 11 juga hampir seluruh tanah kupasannya mengandung arang. Fragmen gerabah ditemukan pada semua kotak yang digali. Temuan cangkang moluska dalam jumlah yang banyak diperoleh dari kotak U4T4 (Sukandar, 2012 : 25).

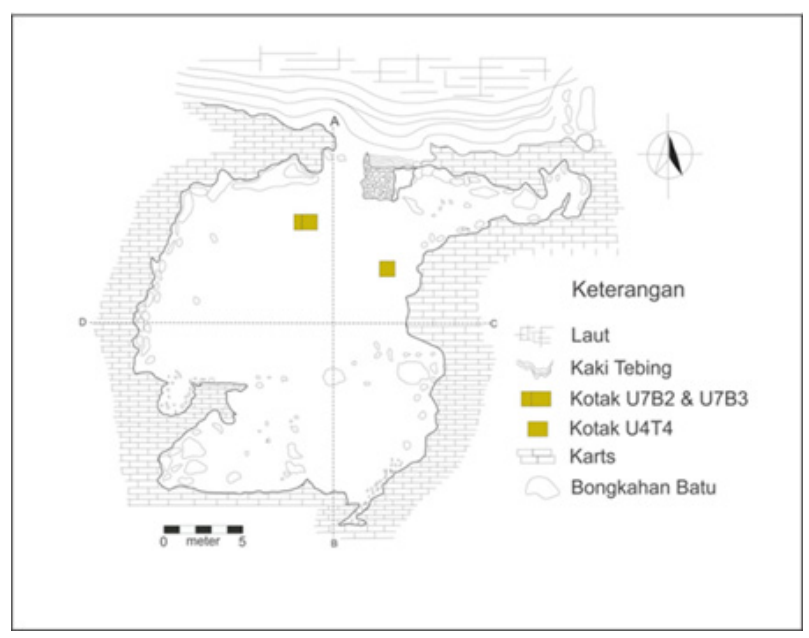

Gambar 12. Denah Lantai Gua Sosoraweru (dokumentasi Balai Arkeologi Jayapura)

\section{Temuan Gerabah dan Keramik}

Temuan gerabah dan keramik pada Situs Kampung Lama Forir ditemukan dalam bentuk pecahan-pecahan. Berdasarkan pengamatan terhadap bentuk tepian, badan dan dasar fragmen gerabah yang ditemukan, diketahui adalah periuk, tempayan dan piring. Teknik pembuatan gerabah jenis periuk dari pengamatan pecahan yang ditemukan dibuat dengan teknik tatap pelandas. Warna bagian permukaan terdiri dari hitam, coklat dan slip merah yang merupakan ciri dari budaya Austronesia. Fragmen keramik yang ditemukan di bekas Kampung Lama Forir berdasarkan pengamatan berbentuk mangkuk dan piring. Mangkuk dari dinasti
Ching dan Ming, sedangkan fragmen piring merupakan keramik dari Eropa. Dilihat dari ragam hiasnya, keramik Eropa memiliki ragam hias berupa flora, sedangkan keramik Cina dari Dinasti Ming memiliki ragam hias geometris. Ragam hias yang ada di kedua jenis keramik tersebut berwarna biru.

Lukisan dinding yang terdapat di tebing-tebing karang sekitar Kampung Forir umumnya berupa gambar cap tangan, manusia, topeng, kura-kura, bintang laut, ikan, titik, motif geometris berupa lingkaran dan segi empat serta tidak teridentifikasi karena sudah aus. Keletakan lukisan berada di ceruk-ceruk tebing pada Situs Tebing Ndamirweru dan Tebing Fotamramo, sedangkan pada Situs Tebing Aintura, lukisannya terletak pada dinding tebing. Warna lukisan umumnya berwarna merah, warna kuning hanya terdapat di Tebing Fotamramo pada lukisan cap tangan, bintang laut dan topeng. Pada Situs Tebing Fotamramo juga ditemukan adanya sisa peti kubur dari kayu, namun bentuknya sudah tidak diketahui lagi. Hal ini mengindikasikan adanya pemanfaatan ceruk di tebing karang sebagai tempat penguburan. Seperti yang ditemukan pula pada Situs Manyaimleudi di Kampung Tomolol, Pulau Misool Kabupaten Raja Ampat. Di situs ini juga terdapat penguburan yang terletak di ceruk-ceruk tebing karang (Tim Peneliti, 2010 : 25).

Berdasarkan temuan yang diperoleh di Gua Sosoraweru, mengindikasikan adanya kegiatan pembakaran di ketiga kotak galian dengan ditemukannya burn clay dan fragmen kulit/lapisan batu bekas tungku pembakaran. Pada kotak U4T4, bahkan dijumpai 6 buah bongkahan 
batu seukuran kepalan tangan orang dewasa. Batu-batu tersebut kemungkinan merupakan dasar atau penopang batu tungku pembakaran.

Ditemukannya butiran kapur pada ketigakotak(U4T4,U7B2,U7B3)danbekas pembakaran cangkang kerang dalam jumlah yang banyak mengindikasikan bahwa situs ini merupakan tempat memproduksi kapur dari cangkang kerang. Saat pembuatan kapur sirih ini disertakan pula daun-daun dari tanaman Urerarina dalam pembakarannya. Kapur sirih dibuat sebagai pelengkap dari tradisi kunyah pinang di Papua. Tradisi kunyah pinang ini diduga diperkenalkan oleh para penutur Austronesia.

Temuan gerabah pada hasil ekskavasi berupa pecahan-pecahan pada bagian badan dan tepian baik berhias maupun polos. Fragmen-fragmen gerabah yang ditemukan berwarna hitam dan coklat. Pada beberapa fragmen terdapat bekas pembakaran berupa jelaga. Hal ini menunjukkan bahwa manusia pendukung situs Gua Sosoraweru telah mengenal gerabah, bahkan telah memanfaatkannya. Berdasarkan pengamatan terhadap fragmen yang ditemukan dibuat dengan teknik tangan, hal ini terlihat dari adanya cekungan bekas tekan jari pada permukaan dalam.

Lukisan dinding yang terdapat di Gua Sosoraweru terletak di langit-langit gua. Gambar yang ada berupa lukisan abstrak dan bentuk geometris seperti garis-garis yang membentuk segi empat dan segi tiga. Namun lukisan-lukisan ini sudah pudar dan aus. Lukisan dinding di Gua Sosoraweru berwarna hitam. Diperkirakan lukisan berwarna hitam lebih muda umurnya dibandingkan warna merah. Di sekitar Teluk Berau, lukisan warna hitam lebih jarang ditemukan dan lukisan tangan tidak muncul lagi. Roder membedakan lukisan warna hitam ini dalam dua aliran, yaitu gaya Ota II dan gaya Sosorraveru. Gaya yang terakhir ini memiliki ciri lukisan perahu yang hampir tidak pernah ditemukan dalam lukisan warna merah (Arifin, 1992: 85). Gaya Sosorraveru ini kemungkinan mengacu pada nama Gua Sosoraweru yang juga terdapat lukisan berwarna hitam. Akan tetapi pada pengamatan di langit-langit gua, lukisan perahu yang disebutkan, tidak ditemukan. Hal ini disebabkan oleh kondisi lukisan yang sudah aus serta langit-langit gua yang telah ditumbuhi jamur.

Gua Sosoraweru merupakan gua yang cukup besar, terletak pada sisi lereng tebing dengan mulut gua berada pada ketinggian kurang lebih 7 meter di atas permukaan laut, menghadap ke arah utara. Gua ini berjarak sekitar 4 meter dari laut yang ada di depannya. Sumber air tawar terletak lebih kurang 300 meter ke arah barat dari gua. Intensitas cahaya yang masuk ke dalam gua ini tidak merata ke seluruh ruang gua, hanya di sekitar mulut gua saja yang mendapat penerangan yang cukup bagus, selebihnya gelap. Lantai gua rata dan kering di bagian depan namun di bagian belakang miring dan lembab. Langit-langit gua di bagian belakang cukup tinggi, akan tetapi pada bagian depan relatif rendah sehingga untuk ukuran orang dewasa pada beberapa bagian harus merunduk.

Dilihat dari karakteristik yang ada, gua ini tidak cukup ideal sebagai hunian, meskipun dari data arkeologi yang ada diperoleh temuan yang mengindikasikan 
gua hunian seperti, sisa cangkang moluska dari jenis yang bisa dimakan, fragmen gerabah dan sisa-siasa pembakaran.

Berdasarkan temuan yang diperoleh dari penggalian yang telah dilakukan, pemanfaatan Gua Sosoraweru lebih menggambarkan sebagai situs penyimpanan dan produksi kapur sirih dari cangkang kerang. Dengan bukti ditemukannya fragmen cangkang kerang yang dibakar, butiran kapur, fragmen kulit/lapisan batu bekas tungku pembakaran dan burn clay. Hal tersebut memberikan kejelasan tentang adanya aktivitas kebiasaan dari pengaruh budaya Austronesia. Salah satu di antaranya yaitu tradisi kunyah pinang yang menggunakan kapur sirih dari cangkang kerang.

\section{PENUTUP}

Dengan demikian, dari hasil survei yang telah dilakukan di Kampung Lama Forir, jejak budaya Austronesia yang ditemukan berupa fragmen gerabah berslip merah. Sedangkan, di situs lukisan dinding tebing di sekitar Kampung Forir diperoleh data arkeologi berupa, sistem penguburan ceruk serta lukisanlukisan dinding tebing yang menunjukkan adanya pengaruh budaya Austronesia. Dari hasil ekskavasi di Gua Sosoraweru, diperoleh kesimpulan bahwa pada masa lampau, gua ini pernah dimanfaatkan oleh manusia sebagai tempat penyimpanan dan produksi kapur sirih dari eksploitasi cangkang kerang. Kapur sirih adalah pelengkap pada saat makan pinang yang merupakan tradisi dari budaya Austronesia. 


\section{DAFTAR PUSTAKA}

Arifin, Karina. 1992. Lukisan Batu Karang di Indonesia: Suatu Evaluasi Hasil Penelitian. Jakarta: Lembaga Penelitian Universitas Indonesia.

Awe, Rokus Due. 1996. Penelitian Arkeometri di Situs-Situs Kokas, Kabupaten Fakfak Propinsi Irian Jaya. Laporan Penelitian Arkeologi. Balai Arkeologi Jayapura.

Mahmud, M. Irfan. 2011. “Jejak Austronesia, Melanesia, dan Tradisi Sejarah Berlanjut di Papua”, dalam Austronesia dan Melanesia di Nusantara: Mengungkap Asal Usul dan Jati Diri dari Temuan Arkeologis. Yogyakarta: Penerbit Ombak. HIm. 43-68.

Simanjuntak, Truman. 2011. "Austronesia Prasejarah di Indonesia", dalam Austronesia dan Melanesia di Nusantara: Mengungkap Asal Usul dan Jati Diri dari Temuan Arkeologis. Yogyakarta: Penerbit Ombak. HIm. 1-22.

Sukandar, Sri Chiirullia. dan Zubair Mas'ud. 2012. "Ekskavasi Situs Gua Sosoraweru di Distrik Kokas, Kabupaten Fakfak, Provinsi Papua Barat”. Laporan Penelitian Arkeologi. Balai Arkeologi Jayapura.

Suroto, Hari. 2010. Prasejarah Papua. Denpasar: Udayana University Press.

Tanudirjo, Daud Aris. 1995. "Kajian Budaya Bendawi Modern dan Arkeologi" dalam Artefak No.15/ Agustus 1995. Jurusan Arkeologi Universitas Gadjah Mada. HIm. 12-20

Tanudirjo, Daud Aris. 2011. "Interaksi Austronesia-Melanesia: Kajian Interpretasi Teoritis", dalam M. Irfan Mahmud dan Erlin Novita Idje Djami (ed.), Austronesia dan Melanesia di Nusantara: Mengungkap Asal Usul dan Jati Diri dari Temuan Arkeologis. Yogyakarta: Penerbit Ombak. HIm. 23-31.

Tim Peneliti, 2009. "Penelitian Lukisan Dinding di Kawasan Kokas Fakfak". Laporan Penelitian Arkeologi. Balai Arkeologi Jayapura.

Tim Peneliti, 2010. Penelitian Prasejarah di Pulau Misool, Kabupaten Raja Ampat, Provinsi Papua Barat. Laporan Penelitian Arkeologi. Balai Arkeologi Jayapura. 


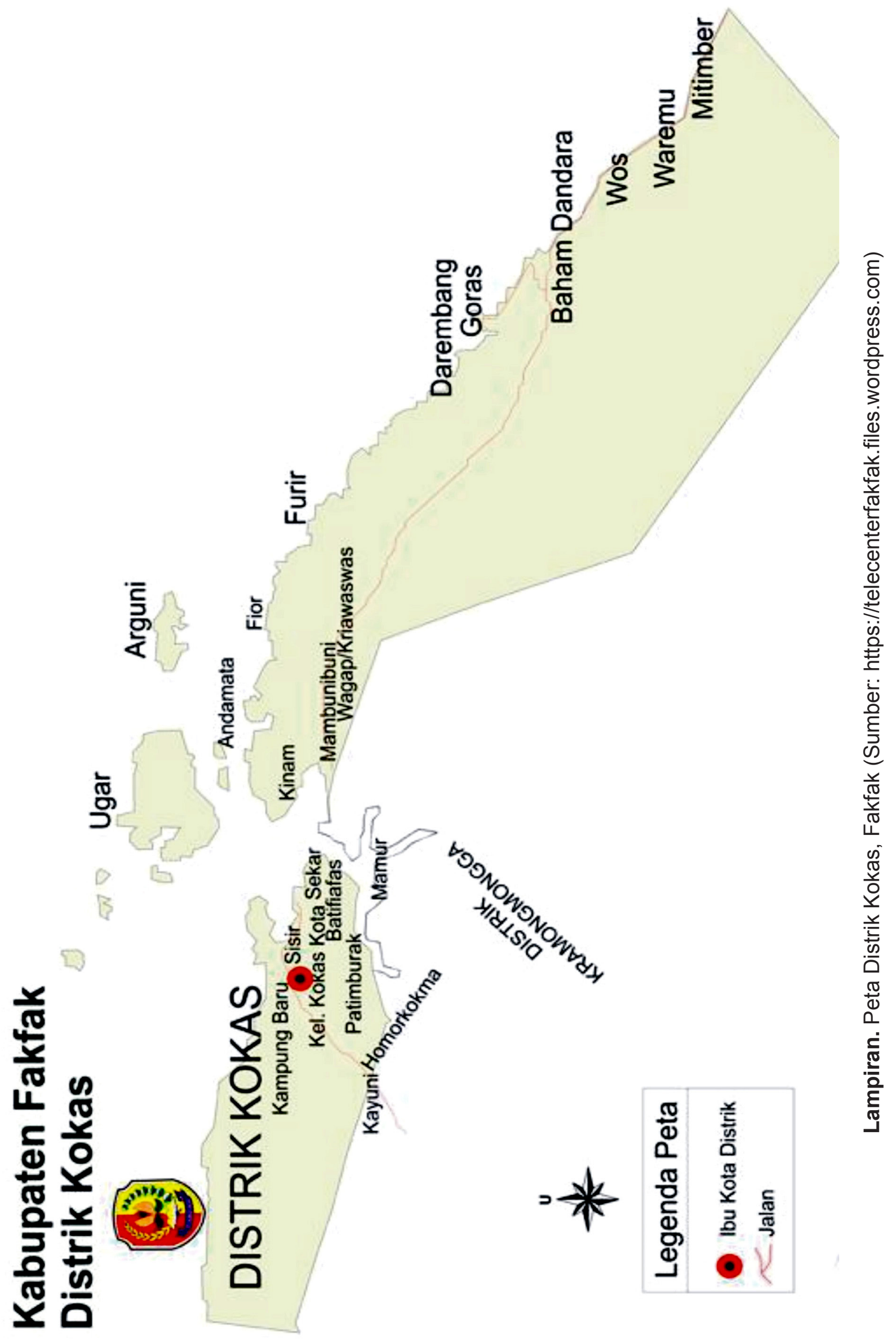

